\title{
Visión aristotélico-tomista de la economía
}

\author{
Rubén Fúnez. \\ Doctor en Filosofía \\ Catedrático de Filosofía y Ética de la Utec \\ ruben,funez@utec.edu.sv
}

\section{Resumen}

En el presente trabajo abordamos la visión económica tanto de Aristóteles como de Tomás de Aquino, con el propósito de encontrar aquel marco categorial que dé luces a la actual situación económica en la que nos encontramos

Palabras clave: Valor de cambio, valor de uso, hurto, rapiña, fraude, usura.

\begin{abstract}
This research project addresses two viewpoints on economics: Saint Thomas Aquinas' and Aristotle's. Its purpose is to find a category framework to provide some enlightenment on the current economic situation.
\end{abstract}

Key words: Exchange value, use value, theft, robbery, fraud, usury

\section{Introducción}

Ya decía Zubiri que no nos ocupamos del pasado por mera erudición, sino para responder a los problemas que la realidad en la que estamos inmersos nos está planteando. Nadie puede ignorar que la economía, del modo como está funcionando, es una realidad que requiere ser repensada.

La situación en la que estamos se mueve entre dos extremos: desde aquellos que piensan que el sistema capitalista, aun con todos sus defectos, es el que ha permitido tanto el bienestar como el progreso de las sociedades, como desde aquellos que creen que este sistema ha tocado fondo, y que del hecho de que carezcamos de alternativas claras no se desprende que no podamos ir ensayando modos diversos a este sistema, de poder hacer frente a los grandes desafíos que tenemos como humanidad.

Precisamente por ello, me he atrevido a dar una primera ojeada al modo como entendieron la economía tanto Aristóteles como Tomás de Aquino. 
Deliberadamente, este trabajo carece de conclusión para animar a los lectores a que ellos mismos puedan sacar sus propias conclusiones.

Si Aristóteles influyo tan notablemente tanto en Smith como en Marx, y tanto los admiradores de aquel como los de este piensan que se trata de autores que siguen teniendo plena actualidad, habrá que decir que la preocupación, tanto aristotélica como tomista, podrá arrojar luz a nuestra problemática actual.

Con respecto a Aristóteles, nos hemos preguntando por su idea de Estado, por su controvertida postura sobre el esclavismo y sobre la economía doméstica y crematística. De santo Tomas hemos retomado sus cuestiones sobre el hurto, la rapiña y la usura.

\section{Origen del Estado}

Aristóteles está interesado en decirnos cuál es el origen del Estado. Origen en el sentido usual del término, como cuando nos preguntamos por el comienzo de algo, pero se trata de un comienzo en el sentido de que está forzando, permitiendo, exigiendo, necesitando el surgimiento de algo. Desde esta perspectiva, cuando nuestro filósofo se plantea el origen del Estado en lo que primariamente está pensando es en esa situación que está exigiendo su aparición. En estos términos hay que entender que comience diciendo que el Estado es una asociación.

Aristóteles piensa que la razón de ser, de toda asociación, es tender hacia su propio fin, y dado que el Estado tiende a su fin es inexorable que sea una asociación, y el carácter de esta asociación viene dada por el fin que persigue.Por eso, si el fin es el más importante, el Estado será la asociación más importante entre todas las asociaciones; por eso nuestro filósofo observa lo siguiente: "Todo Estado es una asociación que tiende al más importante de todos los bienes" (p. 533). De qué bien se trate va a ir quedando claro en la medida en la que vaya hilvanando su idea de Estado. En este momento la noción que es clave que se vaya pensando es la concepción del Estado como una asociación.

Seguidamente el filósofo de Estagira se pregunta por los elementos constitutivos del Estado. La mejor manera de concebir el origen de algo es aprehendiendo sus elementos constitutivos; es como ir viendo emerger de la cosa misma aquello en lo que ella consiste es como colocarse en el seno mismo de la cosa y ver como aparece lo que ella es.

Para Aristóteles, el elemento más simple del Estado es la familia. Es importante tomar en su debida consideración esta postura aristotélica; este pensador griego no cree que el elemento simple del Estado sean los individuos. Es posible como lo veremos después- que los elementos simples de la familia sean el esposo y la mujer, por ejemplo, pero no ocurre lo mismo con el Estado, sino que 
Aristóteles pone como base del Estado a la familia; y vamos a ver en seguida la razón de este modo de pensar.

Una vez establecido que es la familia el elemento básico del Estado, nuestro filósofo se pregunta por el fin de la familia, y establece que es "la necesidad de reproducción que aproxima al hombre a la mujer” (p. 534). De esto habría que señalar al menos dos cosas: en primer lugar, salta a la vista que nuestro pensador tiene claridad que lo que en rigor vincula a las familias es la reproducción y no tanto, por ejemplo, el amor, tema que - dicho entre paréntesis - es de vital importancia en el contexto en el que estamos, en la medida en la que se justifica una serie de uniones recurriendo exclusivamente al amor que pueda existir entre las parejas que deciden estar juntos. Aristóteles evidentemente no es ajeno a esta problemática, y sin embargo tiene una claridad absoluta respecto a que una pareja no constituye una familia, y, por lo tanto, el Estado se funda en familias no en parejas. En segundo lugar, de acuerdo con lo planteado por el filósofo, es el hombre el que se aproxima a la mujer; es el hombre el que anda preocupado en crear a un ser semejante de sí mismo.

Y que sea la reproducción el fin de la familia se entiende en la medida en la que la familia no se agota en sí misma; de hecho el fin de la familia rebasa sus límites naturales en el sentido en que la reproducción tiende a la constitución de muchas más familias, y es — piensa Aristóteles — la "constitución de muchas familias las que forman a los pueblos" (p. 535). Un pueblo, propiamente dicho, es una asociación de familias y es la asociación de muchos pueblos la que forman un Estado.

De este modo Aristóteles nos ha indicado cuáles son los elementos constitutivos de un Estado, a saber, las familias y los pueblos. De este Estado así constituido dice nuestro filósofo que se basta a sí mismo. Aristóteles no estaba pensando en una asociación de Estados; de hecho, el fin último de las familias es la constitución de un Estado y lo que hay que preguntarse es ¿qué significa que el Estado se baste a sí mismo y qué importancia reviste para nuestro filósofo la autosuficiencia del Estado? A lo que por lo pronto contesta que "no puede ponerse en duda que el Estado está naturalmente sobre la familia y sobre cada individuo, porque el todo es necesariamente superior a la parte" (p. 536). Algo no podría ser considerado como todo y al mismo tiempo ser insuficiente, sería una contradicción en los mismos términos algo solo puede ser todo cuando es autosuficiente.

Este carácter de totalidad que reviste la idea de Estado en Aristóteles es la que lo fuerza a pensar acerca de su autosuficiencia. De esta manera, nos vemos forzados a tener que pensar la índole no solo de las familias, sino de los individuos. Para Aristóteles, el ciudadano - y esto hay que afirmarlo con claridad - el individuo no es cualquier individuo, sino que es un ciudadano, es decir, es miembro de un Estado, de tal manera que ve los problemas de la ciudad con los ojos del Estado (Cfr. Ellacuria 2001); solo entiende su fin a partir del fin del Estado. 
El Estado es una realidad necesaria para los individuos, por eso dice Aristóteles que "lo que prueba claramente la necesidad natural del Estado y su superioridad sobre el individuo es, que, si no se admitiera, resultaría que puede el individuo entonces bastarse a sí mismo aislado así del todo como del resto de las partes, pero aquél que no puede vivir en sociedad y que en medio de su independencia no tiene necesidades no puede ser miembro de un Estado; es un bruto o un dios" (p. 536). Es inconcebible, para nuestro pensador, la existencia de un ser humano que no forme parte constitutiva de su ciudad, pero si este es el caso el Estado tiene que contar con los suficientes materiales que puedan estar a disposición de todos y cada uno de los individuos. El bien de los individuos proviene del bien del Estado, por eso Aristóteles exige que el Estado sea absolutamente autosuficiente.

Esta postura, que también la comparte santo Tomas de Aquino, ha sido una de las que mejor fortuna ha tenido a lo largo de la historia de la filosofía. Pasando por G. Tarde y E. Durkheim (cfr. Azevedo, 1942), ha llegado hasta Luis de Sebastián (1988), que, con ella en la mano, echa en cara a los neoliberales la imposibilidad de que del bien de los individuos más capaces para la competencia económica pueda provenir el bien de la sociedad. Porque la parte no es mayor que el todo. Para que a la parte le vaya bien - pensaría Aristóteles - tiene necesariamente que irle bien al todo, al Estado. Por lo tanto, para la pregunta con la que comenzábamos esta sección, a saber, la pregunta por el bien del Estado, la respuesta es que se trata de un bien supremo no solo por ser la del Estado, no solo por ser la del todo, sino por permitirle a sus ciudadanos vivir como tales.

De este modo Aristóteles establece la necesaria relación que debe darse entre el Estado y sus ciudadanos, aunque sea evidente para él que el individuo no podría vivir sin la ciudad, es más, le parece algo contra natura; también es evidente que el Estado no es concebido como un monstruo que termina suprimiendo la realidad individual; de hecho, el Estado es la asociación que permite la realización plena del individuo, de un individuo que, de acuerdo con Aristóteles, "solo él percibe el bien y el mal, lo justo y lo injusto y todos los sentimientos del mismo orden".

\section{De la esclavitud}

Como hemos visto, la asociación más simple en el Estado es la familia, y la familia — dice Aristóteles_- tiene en su base a los esclavos, de tal manera que, cuando tiene que abordar el tema de la economía doméstica, observa que para ser completada tiene que contar con esclavos. Si la relación entre el todo y la parte ha tenido tan buena fortuna a lo largo del pensamiento no ha ocurrido lo mismo con el tratamiento que nuestro pensador da a la esclavitud, y las críticas no es necesario venir a buscarlas en filósofos de última hora, ya en tiempos de Aristóteles hubo pensadores que estimaban que la existencia de esclavos era consecuencia del uso de la fuerza por parte, evidentemente, de los más fuertes, y que por eso eran dignos, los esclavistas, de la cólera de los dioses. 
Aristóteles conoce perfectamente bien las críticas a su pensamiento con respecto a la esclavitud, y, sin embargo, en el tratamiento de lo que llama economía doméstica pone como ya se ha dicho en su base el servicio de los esclavos. Esto, que puede pasar desapercibido, hay que acentuarlo para tener una inteligencia adecuada de la postura aristotélica de la esclavitud, es decir, referir al esclavo al servicio de la economía doméstica.

Como ha tenido la oportunidad de demostrar W. Jaeger (1999), Aristóteles, sobre todo en los escritos de juventud, pensaba que los hombres por naturaleza quieren ser felices; y si es verdad que en la asociación familiar hay una finalidad, hay que decir que no es otra que ser dichosos, pero ocurre - como repetía reiteradamente Aristóteles - que para ser felices es necesario tener cubiertas lo que en su Metafísica llamó, las urgencias vitales.

Desde esta perspectiva observa nuestro pensador que "la propiedad es parte integrante de la familia" (p. 538). Hoy se trata de un tema que ya no despierta las pasiones que pudo haber despertado, por ejemplo, en las décadas de los 70 y 80 . Sin embargo, en aquel tiempo no había mucho consenso acerca de si era licita o no la propiedad; estaban desde los que afirmaban que si pudieran apoderarse de todo El Salvador lo harían, en el caso que se lo permitiera la ley, hasta los que pensaban que la distribución de la propiedad era la única posibilidad de superar los agudos conflictos por los que atravesábamos (Ellacuría, 2005). Sin embargo, Aristóteles es absolutamente claro al respecto: la propiedad es necesaria para las familias.

Pero a qué tipo de propiedad se refiere, o, mejor dicho, ¿qué entiende por propiedad? A lo que contesta afirmando que "la propiedad no es más que un instrumento de la existencia", es decir, la propiedad no es un fin en sí misma, de hecho la propiedad solo se entiende en función de una existencia feliz y dichosa, pero además se trata de un instrumento que, de acuerdo con el uso que se haga de él, así será la existencia que se va a ir consiguiendo. Es decir, Aristóteles entiende que la propiedad, en tanto que instrumento, juega un papel de primera importancia en la forma que adquiera la existencia de las familias que integran a un pueblo.

Sin embargo, cuando se refiere al esclavo, Aristóteles afirma que el "esclavo es una propiedad viva" (p. 538), lo que permite de alguna manera distinguir entre instrumentos y propiedad. El instrumento propiamente está orientado a la producción, de tal manera que el filósofo habla de "instrumentos de producción"; en cambio, la propiedad, por el contrario - observa-, es simplemente para el uso, "el esclavo sólo sirve para facilitar estos actos que se refieren al uso".

¿Qué queremos decir? Que cuando el filósofo de Estagira habla de esclavos no los está considerando como lo que nosotros actualmente entendemos por cosa. Sin embargo, esto no impide que hallan esclavos. Y Aristóteles tiene necesariamente que responder ante esta situación, porque no podemos 
despachar el problema indicando que lo estamos abordando como desde fuera del tiempo, y que Aristóteles no tenía otro medio que justificara la esclavitud, porque - como más arriba hemos dicho- pensadores como Teopompo encontraban en la esclavitud algo que atentaba, incluso, contra la paz de los mismos dioses. Es decir, ya en tiempos de Aristóteles había instrumentos conceptuales para pensar la esclavitud como una aberración, en este caso, de los más fuertes.

Nosotros pensamos que Aristóteles no está más que describiendo y tratando de entender un hecho de la realidad. Veamos. Al menos desde Anaxágoras (Marcuse, 1972), los filósofos griegos habían pensado que los hombres eran poseedores de una poderosa facultad que los capacitaba para instalarse en el seno mismo de las cosas; los sabios griegos pensaban que los hombres podían arrojar luz, tantear y ver la razón de ser de las cosas. y esto no era cosa solo exclusiva de los dioses: todavía el Prometeo encadenado de Esquilo estimaba que aquella capacidad la tenían los hombres como un rapto de los dioses, pero poco a poco y penosamente van a descubrir que se trataba de algo propio de los seres humanos; lo humano era regirse de acuerdo con dicha facultad.

Pero entonces aquí surge un grave problema: ¿qué hacer con aquellos que no son capaces de regirse por el nous, aquellos — dice Aristóteles - "que no pueden llegar a comprender la razón, sino cuando otro se las muestra, pero sin poseerla en sí mismos"; son — dice Zubiri (2007)— “de-mentes", en el sentido que carecen de mente, de nous. Kant seguramente los culparía, les echaría en cara que se comportaran como hombres "menores de edad", poseyendo lo que — según Descartes (2010) - mejor estaba distribuido entre los seres humanos, es decir, la razón. Aristóteles, en cambio, afirma que "cuando uno es inferior a sus semejantes (...) se es esclavo por naturaleza"; y explica "es esclavo por naturaleza el que puede entregarse a otro; y lo que precisamente le obliga hacerse de otro es el no poder comprender la razón, sino cuando otro se la muestra, pero sin poseerla en sí mismo" (p. 539).

En el esclavo, de acuerdo con Aristóteles, hay un poder y un no-poder. Por lo pronto puede entregarse a otro, está de alguna manera inscrito en su ser de hombre poder entregarse a otro, su fin - diría Aristóteles - es precisamente esta entrega. Pero además hay un no-poder que se funda precisamente en aquel poder; por sí mismo no puede hacer uso de la razón, ya que carece de ella. El no-poder consiste precisamente en esta imposibilidad de servirse de la razón.

Es decir, contra lo que piensa Teopompo, no es la fuerza la que constituye al esclavo, más bien pareciera que hay hombres que nacen para ser esclavos. Por eso observa Aristóteles que "es necesario convenir que ciertos hombres serían esclavos en todas partes, y que otros no podrían serlo en ninguna" (542). El que no se puede guiar por su razón no lo podría hacer en ninguna circunstancia y en ningún lugar; no le queda más alternativa que entregarse a otro, lo cual es justo y útil. 


\section{De la adquisición de bienes}

Más arriba afirmábamos que, de acuerdo con Aristóteles, es un derecho de las familias contar con cierta propiedad, esto le fuerza a tener que conceptuar con precisión lo que entiende por propiedad, respecto a lo cual apunta que "toda propiedad tiene dos usos que le pertenecen esencialmente, aunque no de la misma manera: el uno es esencial a la cosa, y el otro no lo es. Un zapato puede a la vez servir para calzar el pie o para verificar un cambio. El que cambia un zapato por dinero o por alimentos con otro que tiene necesidad de él, emplea bien este zapato en tanto que tal, pero no según su propio uso, porque no había sido hecho para cambio" (p. 542). Más de algún comentarista de Aristóteles ha cedido a la tentación de ver en esta clase de textos los orígenes de la filosofía marxista. ${ }^{1}$ Sin embargo, Aristóteles es claro al establecer que se trata de una propiedad, y parte de un hecho sencillo: los seres humanos nos abastecemos de propiedades forzados primariamente por la necesidad que sentimos de ellas; es probable que si no sintiéramos frío no cazaríamos animales para arrebatarles su piel y protegernos de un clima inclemente. Este hecho le parece natural al pensador de Estagira, tan natural como que el fin de un ciudadano sea el de formar parte de un Estado; por eso es que le parece que el uso es parte esencial de la propiedad.

El fin de una propiedad es la de satisfacer una necesidad, pero dado que una propiedad no es una cosa natural, sino que es producto de la invención de los seres humanos, por esta razón es susceptible de contar con más de un fin, y por eso es posible que la propiedad pueda atribuírsele también la posibilidad de ser cambiada; pero ya esta actividad no se inscribe en la naturalidad de la cosa. Digamos que las cosas son "excelentes" cuando su fin es el uso, pero cuando se cambian, aunque el filósofo afirme que lo emplea bien, no se realiza una acción para la cual ha sido creada dicha propiedad.

Pero en el texto que comentamos, Aristóteles introduce un dato que hace pensar que la actividad a la que se está refiriendo no es un mero trueque, es decir, no estamos únicamente cambiando un zapato por un litro de aceite, sino que estamos cambiando un zapato por cinco dólares; estamos cambiando algo que nos pertenece por dinero. Esto nos fuerza a preguntarle al filósofo por la función que cumple el dinero en este tipo de transacciones, y lo primero que indica es que "a medida que estas relaciones de auxilios mutuos se transformaron, desenvolviéndose mediante la importación de los objetos que se carecía y la exportación de aquellos que abundaban, la necesidad introdujo el uso de las monedas" (p. 547).

1 E. Dussel en el comentario que hace de los Grundrisse no se cansa de decir que Aristóteles es masivamente citado por C. Marx. Es evidentísimo que el modo de encarar la realidad económica por parte de Aristóteles, se va a hacer eco no sólo en Marx, porque lo vemos citado en santo Tomás de Aquino y también en Smith. La postura contraria la sostiene Hayek (1990) cuando, sin ningún miramiento, observa que Aristóteles no entendía de economía.

2 En el sentido de la arete, de los griegos. 
El surgimiento del dinero viene a satisfacer una necesidad; digamos que en este sentido el dinero tiene esencialmente un uso, su fin es servir de medio para la realización de las transacciones comerciales. Dijimos más arriba que una de las funciones del Estado es proveer a sus ciudadanos de los materiales necesarios para su vida, desde esta perspectiva, se veía forzado a tener que exportar aquellos excedentes de su producción e importar aquellos productos que, por las razones que fueran, no podían cultivarlos o fabricarlos en el interior de su Estado.

Queremos insistir en que, para Aristóteles, el surgimiento del dinero viene a suplir una necesidad real de los seres humanos, su fin - e insistimos en esto- es servir de medio para el cambio. No obstante, el proceso que va a desencadenar el surgimiento del dinero va a ser para Aristóteles desastroso. Nuestro pensador comienza a plantearlo en los siguientes términos: "El dinero es el que parece preocupar al comercio, porque el dinero es el elemento y el fin de sus cambios, y la fortuna, que nace de esta nueva rama de adquisición, parece no tener realmente ningún límite". Ya no son zapatos los que necesito conseguir, sino que pareciera que lo que necesito es dinero. La relación que se va a establecer ya no es una propiedad por dinero, sino que va a ser dinero por dinero; es justamente a lo que se refiere cuando comenta que "hay fundado motivo para execrar la usura, porque es un modo de adquisición nacido del dinero mismo" (p. 550). Y lo peor - piensa Aristóteles - es que "el dinero no es en sí mismo más que una cosa absolutamente vana, no teniendo otro valor que el que le da la ley, no la naturaleza, puesto que una modificación en las convenciones que tienen lugar entre los que se sirven de él puede disminuir completamente su estimación y hacerle del todo incapaz para satisfacer ninguna de nuestras necesidades". ${ }^{3}$

\section{Santo Tomás de Aquino}

\section{El hurto y la rapiña}

De una cosa está convencido santo Tomás de Aquino: el hurto y la rapiña son pecados que no simplemente se oponen a la justicia, sino que con ellos se perjudica al prójimo en sus bienes. Es decir, para este pensador cristiano no solo es un hecho que los seres humanos poseen bienes, sino que pugnan entre ellos por apropiarse indebidamente de los ajenos, y para ello son capaces de diseñar unas estrategias que pueden fácilmente justificarse.

Es probable que el Aquinate distinga entre el hurto y la rapiña, incluso es probable que esté interesado en indicar una posible jerarquía entre ambos pecados. Sin embargo, es posible que su interés principal resida en justificar la propiedad en manos de los individuos. Justificación más cara cuanto que lo tiene que hacer en

3 Textos de esta naturaleza han llevado a decir a Hayek (1990) que Aristóteles tenía un total desconocimiento del funcionamiento de la economía. Sin embargo, en lugar de deslegitimar la postura aristotélica, el comentario de este economista austriaco tendría que obligarnos a descubrir cuál era realmente el peligro que veía nuestro filósofo en esta hambre irreprimible de dinero. 
diálogo con los santos padres de la Iglesia, en los que se encuentran pensadores que son sumamente críticos respecto a la propiedad. Esta breve introducción únicamente tiene el interés de establecer la perspectiva desde la que vamos a leer al doctor angélico.

La primera cuestión a la que tiene que responder lo enfrenta directamente con Aristóteles en la medida en la que tiene que esclarecer si es natural al hombre la posesión de bienes exteriores. Pero este enfrentamiento hay que evaluarlo con mucho tacto porque, cuando se pregunta por lo natural, no está meramente repitiendo al filósofo griego. Para Aristóteles hubiera sido impensable atribuir la naturaleza de las cosas a la potestad divina; la naturaleza es el principio que explica los cambios de las cosas, es decir, son principios de ellas; en cambio, dice santo Tomas que si se considera a las cosas desde su naturaleza, lo que hay que decir es que se trata de un ámbito que compete a Dios. Y si en lugar de atender a la naturaleza de las cosas se atiende la necesidad a la que tienen que responder, lo que hay que decir — dice el Aquinate — es que "el hombre tiene dominio natural de las cosas exteriores".

La principal tarea de los seres humanos es vivir, es decir, es un ser necesitado, y precisamente por esta necesidad ve en las cosas una dimensión de uso. Las cosas pueden cambiarse, había dicho Aristóteles, pero su finalidad es la de usarse, y como el fin de las cosas es su uso, y en la naturaleza las cosas tienen un único fin, hay que decir que su único fin es satisfacer una necesidad. Es decir, que se usen; y desde esta perspectiva podemos establecer que es natural que los hombres posean bienes. Los seres humanos necesitamos, por ejemplo, una casa donde vivir.

La cuestión que se plantea es si es lícito que poseamos aquellas cosas como propias. Esta es la segunda dificultad que hay que esclarecer. Hace unos quince años un reconocido analista político y dueño de grandes extensiones de tierra decía, con toda honradez, en uno de los canales de televisión de mayor audiencia en El Salvador, que "si pudiera poseer toda la tierra que reconoce la Constitución de la República, sin ningún escrúpulo, la poseería”. Hace unos 120 años, León XIII, ante lo que él denominó "la cuestión social", pensaba que el modo de responder adecuadamente a ella era respetando la propiedad privada, ${ }^{4}$ y el modo como argumentaba estaba apoyado precisamente en santo Tomás de Aquino.

Queremos indicar, con lo anterior, que la cuestión a la que tiene que responder el Aquinate sigue siendo de una gran actualidad. Entonces, ¿cómo tenemos que relacionarnos con las cosas que poseemos?, sean estas casas, tierras, máquinas, dinero, etc. Cuando todas estas cosas entran en relación con los seres humanos, va emergiendo el fin para lo que existen; a fin de una casa es ser habitada, el de la tierra, ser cultivada; el de la máquina, ahorrar tiempo y esfuerzo al

4 El papa afirmaba que "poseer algo en privado como propio es un derecho dado al hombre por la naturaleza" (RN, 4). 
ser humano, etc. Es verdad que son, pero solo realizan lo que son en aquella relación. Esta situación es la que hace decir a santo Tomas que compete a los hombres la potestad de gestión y de disposición de aquellas cosas.

Sin embargo, se trata de una cuestión que no solamente hace referencia a las cosas, sino que es algo que está vinculado con la propia vida de los seres humanos; los hombres hacen su vida entre cosas y con cosas, y para hacerla dice nuestro pensador que atiende diligentemente lo que posee - se administran con mayor orden y además, es lo que permite poder vivir en paz. Vemos que la posesión de cosas juega un papel de primera importancia en la sociedad humana. Sin embargo, esto no obsta para que existan seres humanos que injustamente quieran apropiarse lo que no es suyo: el hurto, la rapiña, el fraude en la compraventa, la usura, etc.

Veamos lo que dice nuestro pensador respecto al hurto y la rapiña. Santo Tomás, respecto al hurto, se plantea tres cosas. En primer lugar, quiere esclarecer qué es el hurto, en segundo, qué clase de pecado es, y en tercero, si hay alguna situación que la justifique. Veamos qué dice con respecto a qué sea el hurto. Esta problemática está situada en el largo tratamiento que el Aquinate hace de la justicia. Y que para lo que aquí nos interesa la entiende como "dar a cada uno lo suyo". Todos tienen que tener lo que requieran para vivir. Vivir es lo que urge, y como hay distintos tipos de vida, cada cual tiene que tener aquello que requiera para vivir en paz. Desde esta perspectiva todo aquello que atenta contra los bienes que otro tiene para hacer su vida atenta contra la justicia. En este sentido, santo Tomás encuentra en el hurto un quebrantamiento a la justicia, en tanto que usurpa lo ajeno. Hay situaciones en las que se puede uno robar a sí mismo, pero no es el caso en relación con el hurto. Para que este ocurra, alguien tiene que apropiarse de lo que es de otro. En este sentido, se puede hurtar un trozo de pan, pero también se pueden hurtar millones de dólares; el hurto no tiene que ver con la cantidad que se usurpa, sino con la apropiación de lo ajeno; 2) este pensador está interesado en decirnos cuál es la esencia del hurto y afirma que se trata específicamente de la sustracción de una cosa. Hay una distinción importante entre individuo y cosa poseída. El hurto no atenta contra la realidad individual, sino contra aquello que posee el individuo. Las cosas por muy importantes que sean, nunca son inherentes a la realidad personal, y 3) por eso, dice que el hurto tiene como nota suya el que se haga ocultamente.

En definitiva, santo Tomás define el hurto como "la sustracción oculta de la cosa ajena". Con respecto a la clase de pecado, se da por entendido que si el hurto quebranta la justicia en tanto que apropiación ilegítima de lo que pertenece a otro, es inexorablemente un pecado. Las cuestiones son las siguientes: ¿qué clase de pecado es el hurto?, ¿contra qué es lo que atenta el hurto?, ¿que es lo que está en juego si en la sociedad en la que vivimos todos nos hurtáramos a todos? 


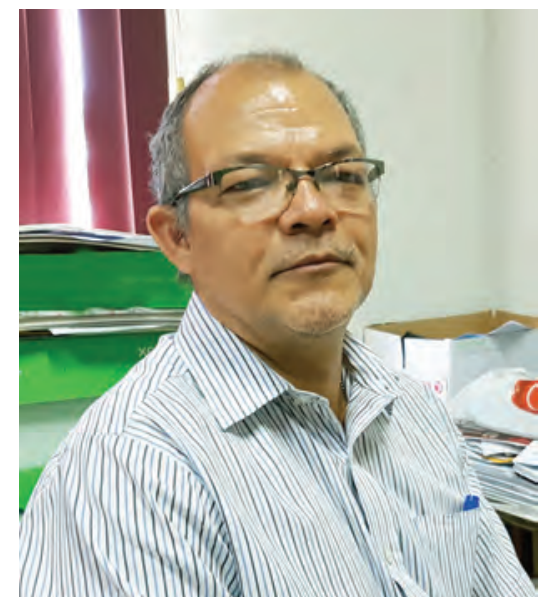

Dr. Rubén Fúnez

Aquí también nuestro pensador se distancia de Aristóteles. Este pensador griego creía que la causa que explicaba la unión entre un hombre y una mujer era la reproducción. Los seres humanos quieren la creación de un ser a su imagen y semejanza y para ello tiene que unirse a una mujer. Es decir, es la reproducción lo que importa en esta unión. Estas distintas familias, en la medida en que se van asociando, van formando la sociedad. Una sociedad diseñada para satisfacerse mutuamente sus necesidades. La sociedad en este sentido, tiene un interés practico en la medida en que permite la relación entre los individuos en vista a la satisfacción de sus necesidades.

Santo Tomas está de acuerdo con que la sociedad está integrada por las familias, pero por unas familias que las une el amor, que las une la caridad, queremos el bien del otro, porque lo amamos; y si nos amamos, lo que en rigor hacemos es manifestar el amor de Dios hacia los hombres, pero si nos robamos mutuamente no solo no nos amamos, sino que tampoco amamos a Dios; y todo aquello que se contrapone al amor de Dios es comprendido como pecado mortal. Cómo se apuntó atrás, desde esta perspectiva, el hurto es pecado mortal.

Sin embargo, ¿podría haber alguna situación que justifique el hurto? es el tercer problema al que el Aquinate tiene que responder. Y digamos desde el inicio de esta cuestión, que el hurto en tanto que hurto no tiene excepción alguna. El hurto es siempre pecado mortal. Entonces todos aquellos que sustraen las cosas ajenas están en pecado mortal. A esto responde Tomás diciendo que, entonces, parece que no toda sustracción es hurto.

Veamos cómo procede; y también aquí, apoyándose en Aristóteles, va más allá de este. Donde el filósofo griego dijo: las cosas inferiores están en función de las cosas superiores; el Aquinate afirmó: las cosas inferiores están ordenadas a la satisfacción de las necesidades humanas. El hombre es un ser de necesidades, entonces las cosas las satisfacen; y esto es una verdad de derecho divino, pero 
por lo visto la distribución y la apropiación de estas cosas han impedido que lleguen a todos y que puedan satisfacer sus necesidades. En estas circunstancias, quien por sus necesidades no satisfechas se encontrara en una situación que ponga en peligro su persona puede, lícitamente, "satisfacer sus necesidades con las cosas ajenas sustrayéndolas, ya manifiesta, ya ocultamente. Y esto no tiene propiamente razón de hurto". Y entonces, qué es Tomás no responde al menos en la cuestión tratada, sin embargo, se infiere de lo dicho: es la apropiación de lo que por naturaleza pertenece a todos.

¿Qué podemos decir respecto a la rapiña? Santo Tomás trata de dos problemas. El primero es la comparación que hace entre hurto y rapiña, y el segundo es la pregunta de si se puede realizar rapiña sin cometer pecado.

La respuesta que da santo Tomás tiene tres niveles en los que va comparando a ambos pecados. Comienza diciendo que tanto el uno como el otro atentan contra la justicia en la medida en que sustraen cosas que por justicia pertenecen a otro. El hurto y la rapiña son acciones injustas y en esto coinciden ambas acciones. Para santo Tomás únicamente puede haber hurto o rapiña cuando se despoja a alguien de aquello que por justicia le pertenece. Podría ocurrir que si alguien posee algo injustamente y es despojado de esta cosa mal habida no sea considerado ni hurto ni rapiña; el Aquinate tiene claridad que se trata de acciones que atentan contra la justicia.

En segundo lugar, el despojo se da en contra de la voluntad de quien es despojado. Si se despoja a alguien de algo con lo que está enteramente de acuerdo en ser despojado, esta acción no sería rapiña; la rapiña y el hurto acontecen contra la voluntad del afectado; nadie quiere ser hurtado. Por eso dice nuestro pensador que siguen siendo comportamientos parecidos. La diferencia se ve justamente en el modo como se manifiesta la involuntariedad del afectado. En el caso del hurto, se afecta a la voluntad sin que esta sea consciente; el hurto ocurre secretamente; en cambio, en el caso de la rapiña, el rapaz infringe violencia al afectado. En este caso es doblemente afectado: no solo se le despoja lo que es suyo sino que además se le despoja violentamente; por eso apunta el filósofo: "por consiguiente, una es la razón del pecado de rapiña y otra la del pecado de hurto, y por esto difieren en especie".

Con respecto a la segunda dificultad que nos habíamos planteado, a saber, si puede haber rapiña sin cometer pecado, digamos que, aunque aparentemente la respuesta parece obvia, no lo es tanto. Si dijimos que la nota esencial de la rapiña es su recurso de la violencia, tenemos que establecer que detrás de esta cuestión podría estar la pregunta acerca de la licitud de la violencia, la licitud de la guerra justa, cuestión reflexionada minuciosamente por santo Tomás. La respuesta a la cuestión que nos ocupa tiene tres momentos: 1) se vuelve a recordar que la rapiña es esencialmente un acto violento, 2) santo Tomás piensa que la violencia solo puede justificarse si es por mandato público, esto es, que el príncipe, ante una causa justa y ante la recta intención de los contendientes, 
autorice la guerra, por lo tanto "quienquiera que arrebata violentamente algo a otro, si es persona particular y no utiliza la pública potestad, obra ilícitamente y comete rapiña”.

\section{El fraude}

la primera cuestión que santo Tomás busca responder es acerca de la licitud de vender una cosa más cara de lo que vale. Aquí hay que llamar la atención acerca del hecho de que se supone la legitimidad del comercio. Si los individuos intercambian cosas es evidente que es porque ese intercambio beneficia a ambos, y es justamente ese mutuo beneficio el que justifica el comercio. Pero además, el Aquinate también reconoce que a las cosas le pertenece un determinado valor y no hay ningún atentado a la justicia si se venden de acuerdo con el valor que deben tener. El problema se plantea en el momento en el que se tiene que recurrir al engaño para sobrevalorar las cosas. ${ }^{5}$ En estas circunstancias, santo Tomás no duda en que es un pecado; y la razón es que "se engaña al prójimo en perjuicio suyo".

Por lo visto, el filósofo piensa que hay engaños con los que no se perjudica a los demás, pero todos aquellos que sí lo hacen es indudablemente pecado. Moralmente un comerciante puede estar en paz, si, al vender, recibe de acuerdo con el valor que tienen las cosas. Un comerciante que venda al mismo precio de lo que compra no estaría realizando una transacción comercial; pero si suma al precio de lo que compra, por el esfuerzo invertido está en todo su derecho de proceder de este modo. ${ }^{6}$ Sin embargo, "si el precio excede al valor de la cosa, o, por el contrario, la cosa excede en valor al precio, desaparecerá la igualdad de justicia. Por tanto, vender una cosa más cara o comprarla más barata de lo que realmente vale es, en sí mismo, injusto e ilícito".

La segunda cuestión que hay que tratar es si la venta se vuelve injusta e ilícita por defecto de la cosa vendida. El sentido popular supone que todo aquel que vende una determinada cosa no lo hace porque la cosa en cuestión sea una maravilla, sino que se hace justamente o porque tiene algún defecto o porque está a punto de padecer algún defecto; y eso parece lo normal. Sin embargo, la normalidad no evita que nos preguntemos con el Aquinate si ese modo de proceder es injusto e ilícito. Y respecto a la dificultad que tratamos, él observa que "si alguien hace esto conscientemente, comete fraude en la venta y, por tanto, ésta resulta ilícita”.

Una tercera cuestión que es abordada por nuestro filósofo es respecto a si el vendedor está obligado a manifestar los defectos de la cosa vendida. Evidentemente, si alguien esconde los defectos que pueda tener una cosa que

5 G. Monterrosa, en su seminario "La dimensión ética de la economía”, recordaba a los participantes que las grandes corporaciones montan su proceder sobre la mentira, y por eso urgía a sus oyentes a no mentir. Los pecados principales de nuestra sociedad se fundan en la mentira. Auditorio De La Paz, Universidad Tecnológica de El Salvador, 03 de setiembre del 2016.

6 En esto santo Tomás coincide con Smith, en tanto que este economista considera que el valor se lo atribuye el trabajo. 
esté urgido en vender, se debe al miedo que le despierta la posibilidad de no encontrar un comprador que quiera hacerse de la cosa en cuestión. Sin embargo, este miedo no es condición suficiente para que se oculten los defectos de las cosas. Si el vendedor está vendiendo la cosa en su justo valor, es decir, si el precio toma en cuenta las dificultades reales de la cosa vendida, en principio no tendría nada que temer, dado que el precio vendido permite al comprador poder solucionar las posibles dificultades que le pueda ocasionar la cosa comprada. A esto es a lo que se refiere santo Tomás cuando afirma que "si el defecto es manifiesto (...) aunque no convenga al vendedor, pueda ser conveniente a otros, y si, por otra parte, el vendedor hace una rebaja en el precio en proporción al defecto, no está obligado a manifestar el defecto de la cosa". Lo grave afirma Tomás es si "el vendedor que ofrece una cosa en venta pone al comprador, por esto mismo, en ocasión de daño o peligro (...) será ilícita y fraudulenta la venta, y el vendedor estará obligado a reparar el daño.”

Finalmente, se pregunta si es lícito en el comercio vender algo más caro de lo que se compró. Se trata de una cuestión cuya respuesta de alguna manera ha ido apareciendo en el tratamiento que se ha hecho de las cuestiones anteriores, por eso responde que "es propio de los comerciantes dedicarse a los cambios de las $\operatorname{cosas}^{7}(.$.$) el lucro, que es el fin del comercio, aunque en su esencia no$ entrañe algún elemento honesto o necesario, tampoco implica por esencia nada vicioso o contrario a la virtud. Por consiguiente, nada impide que ese lucro sea ordenado a un fin necesario o incluso honesto, y entonces la negociación se volverá lícita."

\section{La usura}

Un amigo me refirió que la siguiente anécdota: una mañana se le acercó un compañero de trabajo, del que sabía que desde hace algún tiempo estaba teniendo dificultades económicas; todo avergonzado le preguntó si podía prestarle diez dólares, porque de lo contrario no podría venir al trabajo la próxima semana. Le dijo que sí tenía; y al prestárselos en lo único en lo que insistió fue en que se los devolviera al final del mes. Me comentó que, aunque se le cruzó por la cabeza la posibilidad de decirle que le devolviera once dólares, experimentó una sensación de vergüenza: Este pobre hombre ya tiene dificultad para poder terminar el mes, todo posible interés va a incrementar los problemas que ya tiene. En este caso, lo que de inmediato le pareció justo fue decirle "devolvéme el dinero inmediatamente que te paguen."

Frente a esa sensación de pena se vuelve difícil entender cómo es posible que existan seres humanos que se lucren de ese modo, porque es un modo habitual de vida para muchos "prestamistas". A esta dificultad es a la que responde santo Tomás cuando se hace la pregunta ¿es pecado recibir interés por un préstamo monetario? Es posible que la vergüenza resida en este modo de plantear el

7 Contra Smith habría que decir que el cambio no es que sea propia de la realidad humana, sino que el cambio es propio de un tipo de vida, la del comerciante. 
problema. Es evidente que si se comienza preguntándose si es pecado, lo menos que pueda experimentar sea pena.

Pero veamos cómo trata la dificultad nuestro filósofo. Comienza diciendo que el nombre de usura proviene de esa transacción en la que, además de devolver el grano que se prestó, se da una determinada cantidad de dinero; yo presto diez libras de frijoles y el pago consiste no solo en devolver las diez libras, sino un dólar más. Esa forma de proceder — dice el Aquinate - es injusta en sí misma "porque implica la venta de lo que no existe".

Para responder a la cuestión del préstamo a interés santo Tomás recuerda que Aristóteles pensó que el fin del dinero es exclusivamente para realizar cambios. El ser humano, en cuanto realidad necesitante, se da cuenta de que necesita de las cosas que produce su vecino, mientras que su vecino necesita de las cosas que produce aquel. Es esta necesidad común la que los lleva a intercambiar sus productos, y el dinero es un medio que facilita dicho intercambio. Desde esta perspectiva, dice santo Tomás que "es en sí ilícito percibir un precio por el uso del dinero prestado".

Mi compañero, ¿pudo decirle a su amigo que efectivamente le prestaba los diez dólares que estaba necesitando, pero que a cambio le dejara su bicicleta? Esto no parece ser una dificultad para las miles de casas de empeño que existen en la ciudad; pero al menos hay ser conscientes de que, para algunos, ese modo de proceder no es tan evidente, de tal modo que la segunda cuestión que se plantea santo Tomás es precisamente si es lícito exigir algún otro beneficio por el dinero prestado. Frente a esto responde que si la compensación se exige, se peca contra la justicia, en cambio, "si se recibe sin haberlo exigido y sin que derive de alguna obligación tácita o expresa, sino en concepto de don gratuito, no peca".

\section{Referentes bibliográficos}

Aristóteles, (1967). Obras completas, tomo I, OMEBA, Argentina. Tomás de Aquino. Suma de teología III, cuestiones 66, 77, 78. H. Marcuse (1972). Razón y revolución, Alianza editorial, Madrid. X. Zubiri, (2007). Naturaleza, Historia, Dios, Alianza editorial, Madrid. I Ellacuria, (2003). Escritos filosóficos III, UCA editores, San Salvador. F. H. Hayek (1990). La fatal arrogancia, Unión Editorial, Madrid.

F. Azevedo (1942). Historia de la sociología, Fondo de Cultura Económica, México. L. de Sebastian (1988). La contradicción del neoliberalismo moderno, Cristianisme i justicia, Barcelona. 


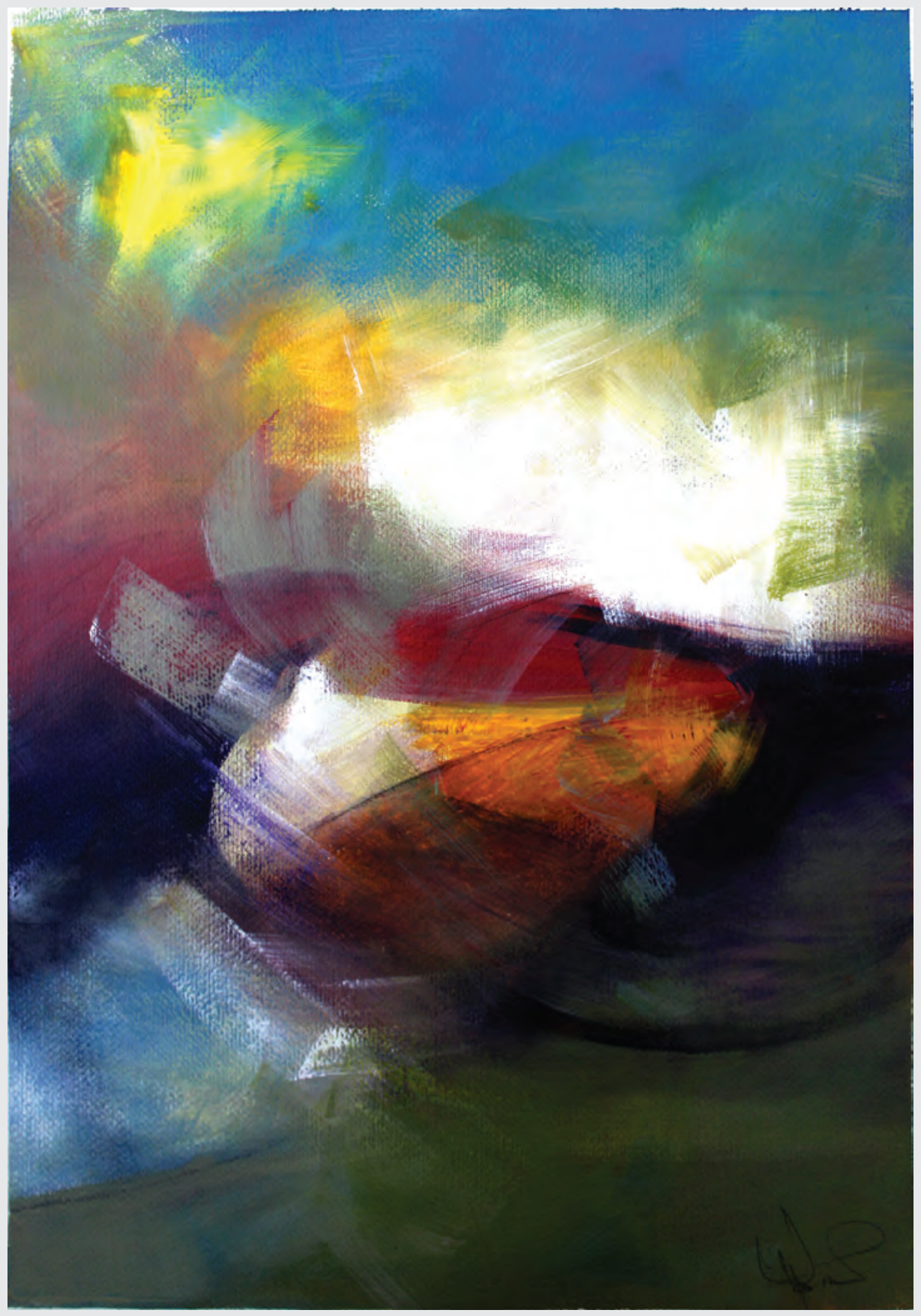

\section{"Abstracción"}

Medidas: 50 x $70 \mathrm{cms}$

Técnica: mixta

Año: 2010-2014 